\title{
Effect of Testosterone on Cisplatin-Induced Nephrotoxicity in Surgically Castrated Rats
}

\author{
Bahar Rostami ${ }^{1,2}$; Mehdi Nematbakhsh ${ }^{1,2,3,}$; Zahra Pezeshki ${ }^{1}$; Ardeshir Talebi ${ }^{1,4}$; Moham- \\ mad Reza Sharifi ${ }^{2}$; Fatemeh Moslemi ${ }^{1}$; Fatemeh Eshraghi-Jazi ${ }^{1}$; Farzaneh Ashrafi ${ }^{1}$ \\ ${ }^{1}$ Water and Electrolytes Research Center, Isfahan University of Medical Sciences, Isfahan, IR Iran \\ 2 Department of Physiology, Isfahan University of Medical Sciences, Isfahan, IR Iran \\ ${ }^{3}$ Institute of Basic and Applied Sciences Research, Isfahan, IR Iran \\ ${ }^{4}$ Department of Clinical Pathology, Isfahan University of Medical Sciences, Isfahan, IR Iran \\ *Corresponding author: Mehdi Nematbakhsh, Water and Electrolytes Research Center, Isfahan University of Medical Sciences, Isfahan, IR Iran. Tel: +98-9131104751, Fax: +98-3137922419, \\ E-mail: nematbakhsh@med.mui.ac.ir
}

Received: June 28, 2014; Revised: July 7, 2014; Accepted: July 10, 2014

Background: Cisplatin (CP) is an important antitumor drug with serious side effects such as nephrotoxicity. Estrogens can affect CPinduced nephrotoxicity; however, the role of testosterone(TS), the main male sex hormone, is not clear.

Objectives: This study aimed to investigate the effect of TS on CP-induced nephrotoxicity in castrated male rats.

Materials and Methods: A total of 54 male Wistar rats were castrated and allocated into eight groups. Groups 1 through 3 respectively received 10,50, and $100 \mathrm{mg} / \mathrm{kg} / \mathrm{wk}$ of TS and group 4 received sesame oil for four weeks; then all four groups received $2.5 \mathrm{mg} / \mathrm{kg} / \mathrm{d} \mathrm{CP}$ for one week. Groups 5 through 8 received the same treatment regimen as groups 1 through 4 during first four weeks but instead of $\mathrm{CP}$, they received saline for one week. Then the animals were sacrificed for biochemical and histopathologic studies.

Results: $\mathrm{CP}$ increased the serum levels of blood urea nitrogen (BUN), creatinine (Cr), and malondialdehyde (SMDA) as well as kidney weight $(\mathrm{KW})$, bodyweight (BW) loss, and kidney tissue damage score(KTDS). It significantly decreased the serum and kidney levels of nitrite and serum level of TS in comparison with the control group $(\mathrm{P}<0.05)$. However, coadministration of CP and low dose of TS significantly decreased the serum levels of BUN as well as $\mathrm{Cr}$ and KTDS $(\mathrm{P}<0.05)$. Administration of high-dose TS alone increased the SMDA level, KTDS, and KW while decreased the BW significantly $(\mathrm{P}<0.05)$.

Conclusions: It seems that testosterone in low dose, i.e. physiologic dose, protects kidneys against CP-induced nephrotoxicity; however, special care is needed in CP therapy of patients with high levels of TS.

Keywords:Testosterone; Castrated Rat; Cisplatin; Nephrotoxicity

\section{Background}

Cis-diamminedichloroplatinum II or cisplatin (CP), an important antineoplastic drug, is widely used for treatment of solid tumors including head and neck, lung, testis, ovary, and breast tumors (1). Unfortunately, it has some side effects such as ototoxicity, gastrotoxicity, myelosuppression, and allergic reactions. The major side effect of CP is nephrotoxicity (2), which occurs in about $30 \%$ of patients treated with CP due to tubular toxicity, inflammation, oxidative stress, and change in the renal blood flow (3-6). Various agents such as vitamins $C$ and $\mathrm{E}$, losartan, L-arginine, magnesium, and erythropoietin have been proposed as nephroprotective agents against CP-induced nephrotoxicity (7-14). Previous studies showed that CP-induced nephrotoxicity is sex-related and intensity of kidney damage in males treated with CP is significantly greater than that in females $(15,16)$. At first sight, it seems that the sex differences in CP-induced nephrotoxicity must be related to sex hormones; however, according to our previous study, estrogen did not have protective effect against CP-induced nephrotoxicity and might promote toxicity in female rats (17). The role of testosterone (TS) against CP-induced nephrotoxicity is not yet documented. It seems that TS affects CP effectiveness in proximal tubule with vasodilatory effect on renal afferent arterioles via expression of androgenic receptors and activation of nitric oxide synthase (NOS) (18). Previously, it was reported that TS enhances kidney susceptibility to ischemia-reperfusion injury and on the other hand, it had protective role in ischemia-reperfusion-induced acute kidney injury (19, 20). We hypothesized that TS might affect CP-induced nephrotoxicity,

\section{Objectives}

This study aimed to examine the role of different doses of TS in response to CP-induced nephrotoxicity in castrated rats.

Copyright (C) 2014, Nephrology and Urology Research Center; Published by Kowsar. This is an open-access article distributed under the terms of the Creative Commons Attribution-NonCommercial 4.0 International License (http://creativecommons.org/licenses/by-nc/4.0/) which permits copy and redistribute the material just in noncommercial usages, provided the original work is properly cited. 


\section{Materials and Methods}

\subsection{Animals}

The investigation was performed on 54 adult male Wistar rats (Animal Center, Isfahan University of Medical Sciences, Isfahan, Iran) with the mean weight of $182 \pm 2.7$ g. The rats were housed at the temperature of $23^{\circ} \mathrm{C}$ to 25 ${ }^{\circ} \mathrm{C}$ with free access to water and chow. The experimental procedures were approved by the Isfahan University of Medical Sciences Ethics Committee.

\subsection{Experimental Protocol}

The rats were anesthetized with intraperitoneal injection of ketamine $(75 \mathrm{mg} / \mathrm{kg}$ ). A midline incision of about 2 -cm length was made in the subabdominal region. The epididymis and testis were pulled out, vas deferens and spermatic blood vessels were ligated, and finally, testes were removed. One week later, they were randomly allocated to eight experimental groups. Groups 1, 2, and 3 received 10,50 , and $100 \mathrm{mg} / \mathrm{kg} / \mathrm{wk}$ intramuscular TS enanthate (Aburaihan Co., Tehran, Iran), respectively, for four weeks and at the end of the third week, the animals received $2.5-\mathrm{mg} / \mathrm{kg} / \mathrm{d}$ CP intraperitoneally for seven days. Group 4 (positive control) received CP plus sesame oil instead of TS. Groups 5, 6, and 7 received the same treatment regimen as groups 1 through 3, respectively, for four weeks; however, they received saline instead of $\mathrm{CP}$ for the following seven days. Group 8 (negative control) received sesame oil and saline instead of TS and CP, respectively. When $\mathrm{CP}$ injection was initiated, the animals were weighed daily. At the end of the study, blood samples were obtained and then the animals were sacrificed. Left and right kidneys were removed and weighed immediately for histopathologic investigation and measurements.

\subsection{Measurements}

The serum creatinine $(\mathrm{Cr})$ and blood urea nitrogen (BUN) levels were determined using quantitative diagnostic kits (Pars Azmoon, Iran). The serum and kidney levels of nitrite (stable NO metabolite) were measured using a colorimetric ELISA kit (Promega Corporation, USA) that involved the Griess reaction. The serum and kidney levels of malondialdehyde (MDA) were determined by $10 \%$ trichloroacetic acid (TCA) and $0.67 \%$ thiobarbituric acid (TBA). TCA test is based on protein deposition. MDA reacted with TBA and created pink complex. The serum level of TS was measured using enzyme immunoassay ELISA kit (Diagnostics Biochem Canada Inc., Canada).

\subsection{Histopathological Procedures}

The left kidney was fixed in 10\% neutral formalin solution and embedded in paraffin for hematoxylin and eo- sin staining to examine the tubular damage. A pathologist who was completely unaware of the study protocol and administered medications evaluated the damage. Kidney tissue damage score (KTDS) was graded from I to IV, based on the intensity of tubular lesions (hyaline cast, debris, vacuolization, flattening and degeneration of tubular cells, and dilatation of tubular lumen), while zero was assigned to normal tubules without any damage.

\subsection{Statistical Analysis}

Data were expressed as mean \pm standard error of means (SEM). Comparison of the groups with regard to the bodyweight (BW) loss, kidney weight (KW); and levels of BUN, Cr, MDA, TS, and nitrite were performed by one-way ANOVA followed by post hoc Dunnett's test when applicable. Comparison between positive and negative control grous was performed by t-Student test. The histopathologic damage score of the groups was compared by the Kruskal-Wallis and Mann-Whitney U tests.

\section{Results}

\subsection{Effect of Cisplatin on Renal Toxicity}

Comparison of the positive and negative control groups (group 4 and group 8, respectively) demonstrated that in the positive control group, KW, KTDS, and serum levels of BUN, Cr, and MDA had increased while the serum TS level, serum and kidney tissue levels of nitrite, and BW had decreased significantly $(\mathrm{P}<0.05)$. These data confirmed CPinduced nephrotoxicity (Figure 1).

\subsection{Effect of Testosterone on Cisplatin-Induced Nephrotoxicity}

Comparison between the case groups (groups 1, 2, and 3 ) and the positive control (group 4) indicated that the serum levels of BUN and $\mathrm{Cr}$, and KTDS had significantly decreased in group 1 (group treated with low-dose TS plus CP) in comparison with group 4 (positive control group) $(\mathrm{P}<0.05)$ (Figure 2$)$. According to these findings, low-dose TS can prevent CP-induced nephrotoxicity. As expected, significant increase in serum TS level was detected in group 3 (group treated with high-dose TS) in comparison with the positive control group $(\mathrm{P}<0.05)$ (Figure 2). Although the serum levels of TS in groups 1 and 2 were higher than that in group 4, these differences were not statistically significant (Figure 2). No significant differences were observed among the groups with respect to other parameters (Table 1).

\subsection{Effect of Testosterone on Renal Toxicity}

Comparison between TS alone treated groups (groups 5, 6 , and 7) in one hand and negative control group (group 8 ) on the other hand indicated no significant differences in serum levels of BUN, Cr, and nitrite as well as tissue lev- 
els of nitrite and MDA (Table 2). Nevertheless, increase in serum MDA, KW, and KTDS were observed in high-dose TS (100 mg/kg/wk) group $(\mathrm{P}<0.05)$. The BW reduced in TS treated groups and this reduction was significant only in group 7 in comparison with group $8(\mathrm{P}<0.05)$. The serum level of TS was significantly higher in groups 6 and 7 (P $<0.05)$. The samples of tissue images for all groups are demonstrated in Figure 3.

Figure 1. Measured Parameters in Positive and Negative Controls

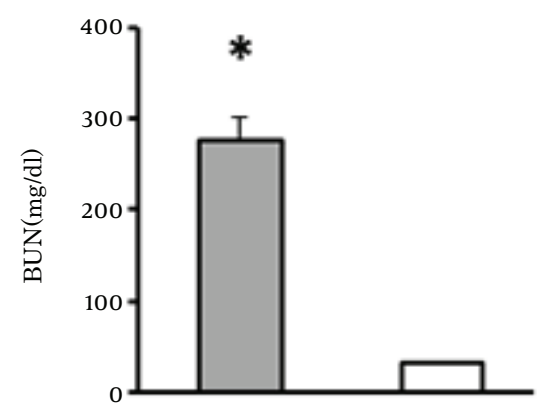

$\mathrm{CP}$
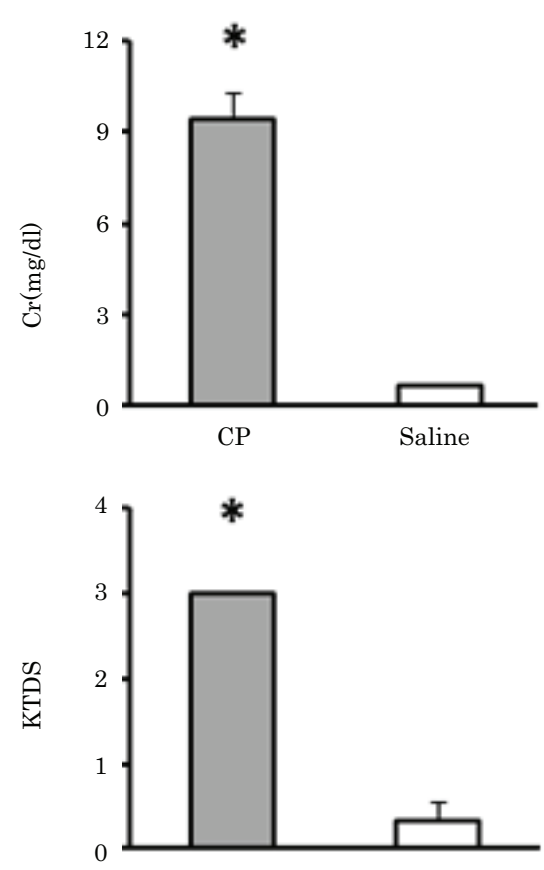

$\mathrm{CP}$



CP
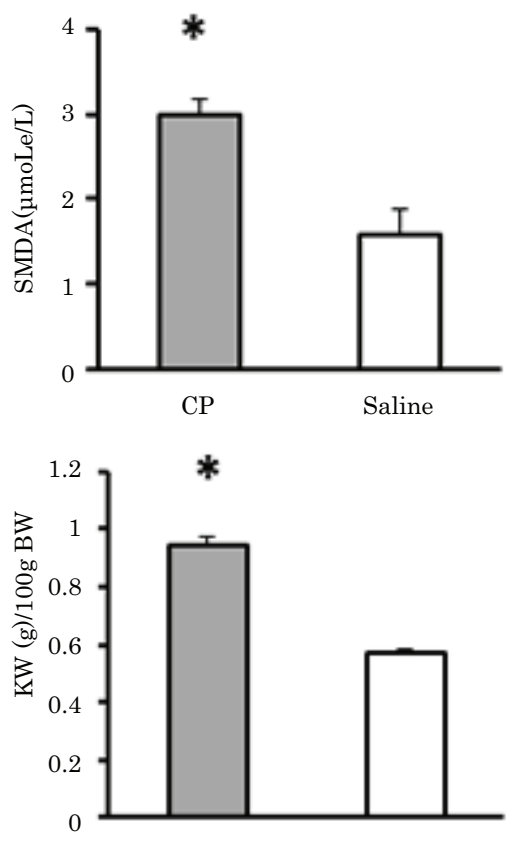

$\mathrm{CP}$



$\mathrm{CP}$

Saline



$\mathrm{CP}$
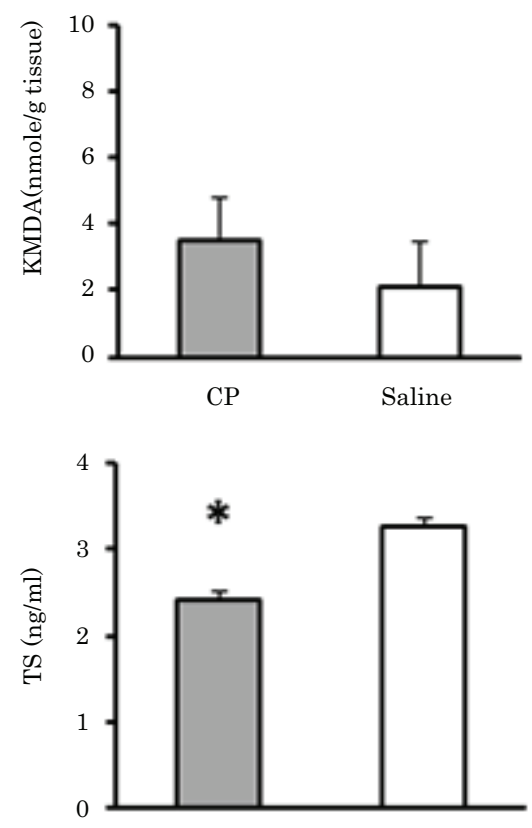

$\mathrm{CP}$

Saline

Significant difference between positive and negative control groups $(\mathrm{P}<0.05)$. Abbreviations: BUN, blood urea nitrogen; $\mathrm{Cr}$, creatinine; $\mathrm{SN}$, serum nitrite; SMDA, serum malondialdehyde; TS, testosterone; KN, kidney tissue levels of nitrite; KMDA, kidney tissue levels of malondialdehyde; KW, kidney weight; $\Delta \mathrm{BW}$, bodyweight changes; and KTDS, kidney tissue damage score. 
Figure 2. Serum Levels of Blood Urea Nitrogen, Creatinine, and Testosterone and Kidney Tissue Damage Score in Testosterone Plus Cisplatin and Cisplatin Alone Groups.

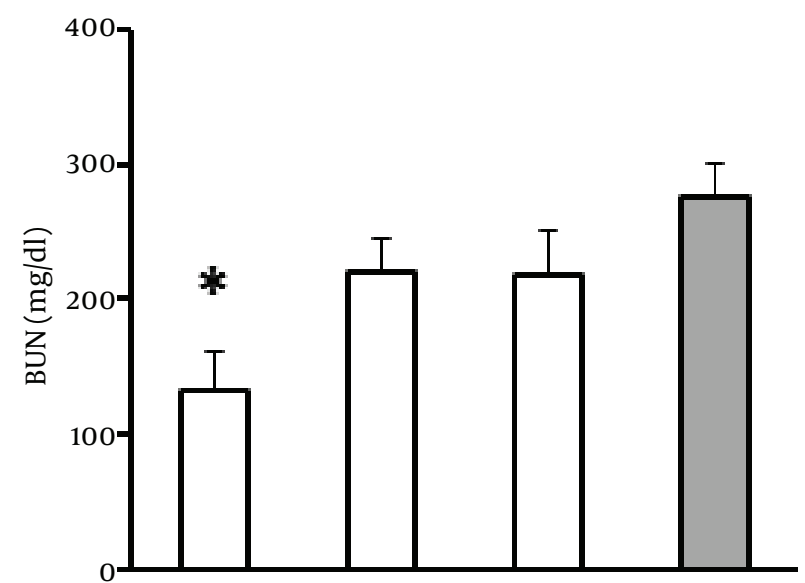

$\mathrm{CP}+\mathrm{TS} 10 \quad \mathrm{CP}+\mathrm{TS} 50 \quad \mathrm{CP}+\mathrm{TS} 100 \quad \mathrm{CP}$

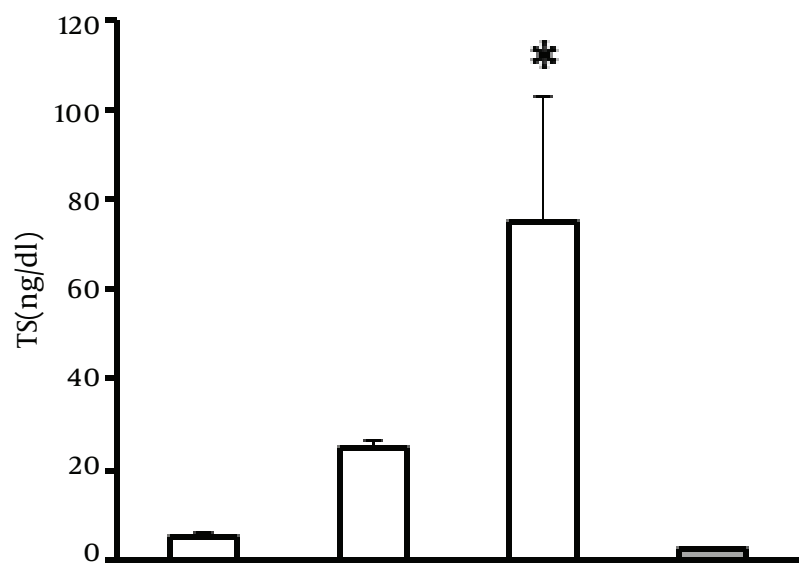

$\mathrm{CP}+\mathrm{TS} 10$

$\mathrm{CP}+\mathrm{TS} 50 \quad \mathrm{CP}+\mathrm{TS} 100$

$\mathrm{CP}$
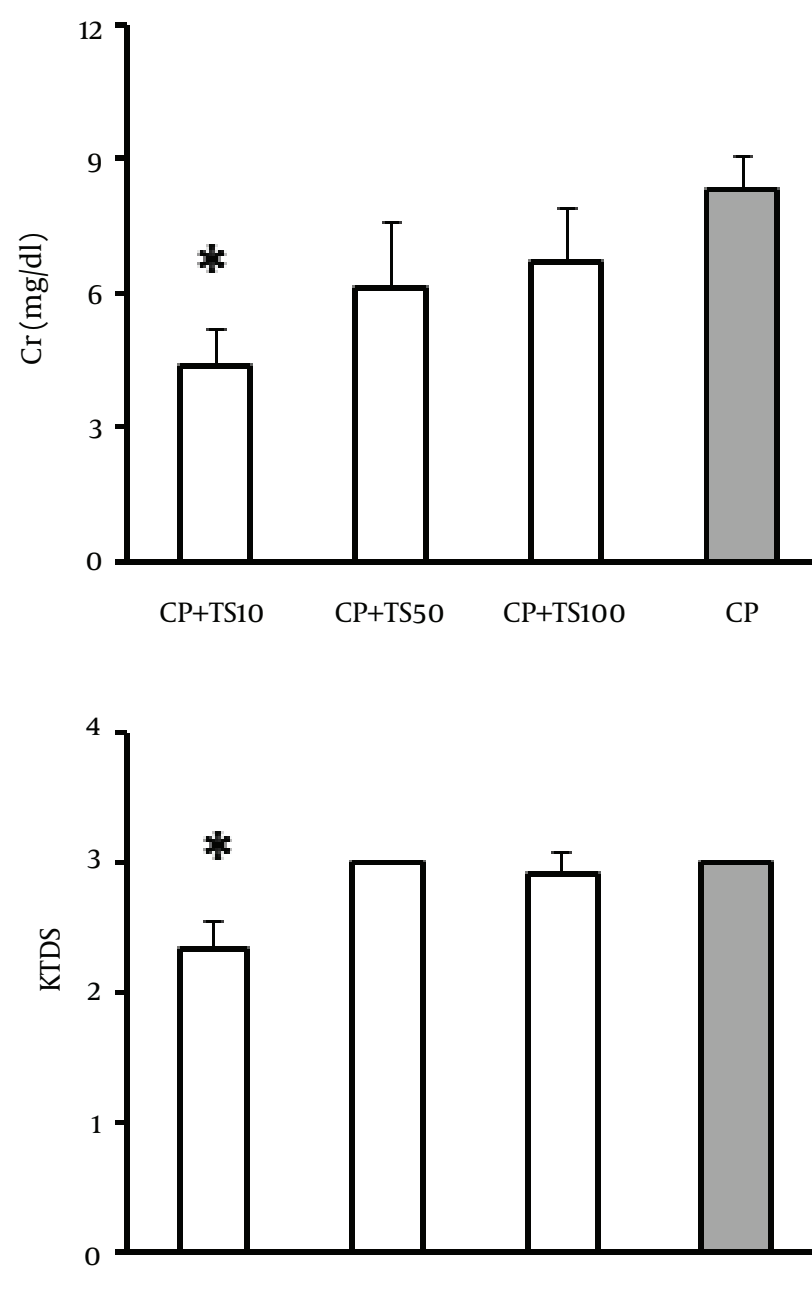

$\mathrm{CP}+\mathrm{TS} 10 \quad \mathrm{CP}+\mathrm{TS} 50 \quad \mathrm{CP}+\mathrm{TS} 100 \quad \mathrm{CP}$

Significant difference from group 4. Abbreviations: BUN, blood urea nitrogen; Cr, creatinine; TS, testosterone; and KTDS, kidney tissue damage score.

Table 1. Measured Parameters in Groups 1 Through 4 a,b

\begin{tabular}{|c|c|c|c|c|c|c|}
\hline Group $^{c}$ & $\mathrm{SN}, \mu \mathrm{moL} / \mathrm{L}$ & $\begin{array}{c}\mathrm{KN}, \mu \mathrm{moL} / \mathrm{g} \\
\text { tissue }\end{array}$ & SMDA, $\mu \mathrm{moL} / \mathrm{L}$ & $\begin{array}{l}\text { KMDA, nmole/g } \\
\text { tissue }\end{array}$ & $\mathrm{KW}, \mathrm{g} / \operatorname{100g} \mathrm{BW}$ & $\Delta \mathrm{BW}, \mathrm{g}$ \\
\hline 1. $C P+T S 10$ & $14.69 \pm 2.224$ & $0.10 \pm 0.01$ & $2.71 \pm 0.32$ & $1.14 \pm 0.32$ & $0.97 \pm 0.04$ & $-15.33 \pm 2.80$ \\
\hline 2. CP + TS50 & $21.39 \pm 5.71$ & $0.13 \pm 0.02$ & $3.08 \pm 0.46$ & $1.77 \pm 0.52$ & $0.89 \pm 0.04$ & $-15.28 \pm 4.14$ \\
\hline 3. CP+TS100 & $17.81 \pm 4.07$ & $0.13 \pm 0.01$ & $2.56 \pm 0.35$ & $5.91 \pm 2.66$ & $0.92 \pm 0.04$ & $-15.9 \pm 2.27$ \\
\hline 4. $C P$ & $12.78 \pm 2.56$ & $0.1 \pm 0.01$ & $2.98 \pm 0.19$ & $3.54 \pm 1.23$ & $0.94 \pm 0.03$ & $-21.83 \pm 3.23$ \\
\hline
\end{tabular}

a Abbreviations: CP, cisplatin; TS, testosterone; SN, serum nitrite; KN, kidney nitrite; SMDA, serum malondialdehyde; KMDA, kidney tissue malondialdehyde; $\mathrm{KW}$, kidney weight; and $\Delta \mathrm{BW}$, bodyweight changes.

$\mathrm{b}_{\mathrm{C}}$ No significant differences were observed between these groups.

${ }^{\mathrm{c}}$ TS10, TS50, and TS100 stand for treatment with testosterone doses of 10,50 , and $100 \mathrm{mg} / \mathrm{kg} / \mathrm{wk}$, respectively. 
Rostami B et al.

\begin{tabular}{|c|c|c|c|c|c|c|c|c|c|c|}
\hline Group $^{c}$ & $\begin{array}{c}\text { BUN, mg/ } \\
\text { dL }\end{array}$ & $\mathrm{Cr}, \mathrm{mg} / \mathrm{dL}$ & $\mathrm{SN}, \mu \mathrm{moL} / \mathrm{L}$ & $\underset{\text { Kissue }}{\mathrm{KN}, \boldsymbol{m o L} / \mathrm{g}}$ & $\begin{array}{l}\text { SMDA, } \\
\mu \mathrm{moL} / \mathrm{L}\end{array}$ & $\begin{array}{c}\text { KMDA, } \\
\text { nmoL/g }\end{array}$ & KTDS & $\mathbf{K W}, \mathbf{g}$ & $\Delta \mathrm{BW}, \mathrm{g}$ & $\mathrm{TS}, \mathbf{n g} / \mathbf{m L}$ \\
\hline 5. TS10 & $34.42 \pm 3.355$ & $0.72 \pm 0.05$ & $27.63 \pm 5.53$ & $0.22 \pm 0.02$ & $2.77 \pm 0.48$ & $1.51 \pm 0.73$ & $0 \pm 0$ & $0.71 \pm 0.03$ & $-1.66 \pm 1.38$ & $8.67 \pm 3.77$ \\
\hline 6. TS50 & $26.66 \pm 3.75$ & $0.87 \pm 0.1$ & $18.11 \pm 6.07$ & $0.22 \pm 0.01$ & $2.64 \pm 0.52$ & $0.89 \pm 0.31$ & $0.67 \pm 0.21$ & $0.68 \pm 0.04$ & $-3.83 \pm 1.32$ & $61.12 \pm 0.54^{b}$ \\
\hline 7. TS100 & $41.83 \pm 5.79$ & $0.86 \pm 0.24$ & $22.1 \pm 6.59$ & $0.17 \pm 0.01$ & $3.37 \pm 0.23^{b}$ & $1.45 \pm 0.49$ & $1.5 \pm 0.22^{b}$ & $0.94 \pm 0.08^{b}$ & $-5.75 \pm 1.6^{b}$ & $89.85 \pm 6.08^{b}$ \\
\hline 8. Saline & $32.08 \pm 1.97$ & $0.7 \pm 0.02$ & $23.16 \pm 6.001$ & $0.23 \pm 0.01$ & $1.59 \pm 0.29$ & $2.12 \pm 1.34$ & $0.33 \pm 0.21$ & $0.57 \pm 0.01$ & $2 \pm 3.15$ & $3.25 \pm 0.11$ \\
\hline
\end{tabular}

Figure 3. Histopathologic Findings in Kidney Tissue of the Eight Experimental Groups
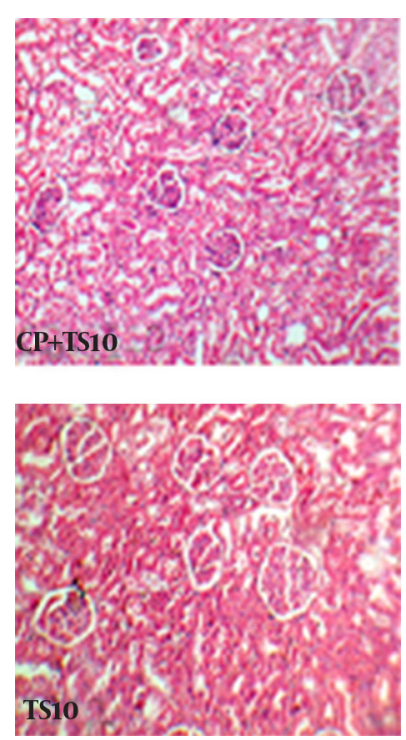
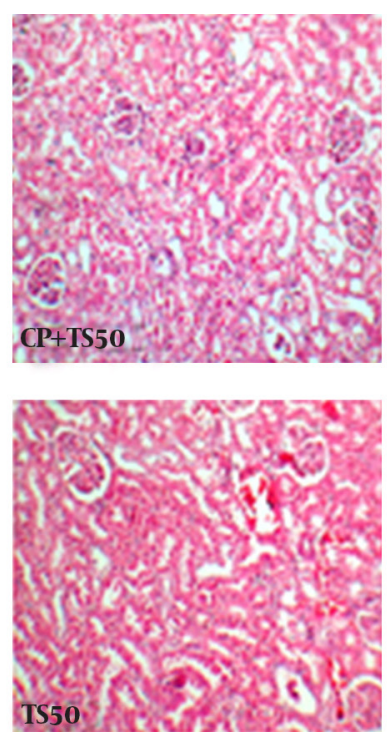
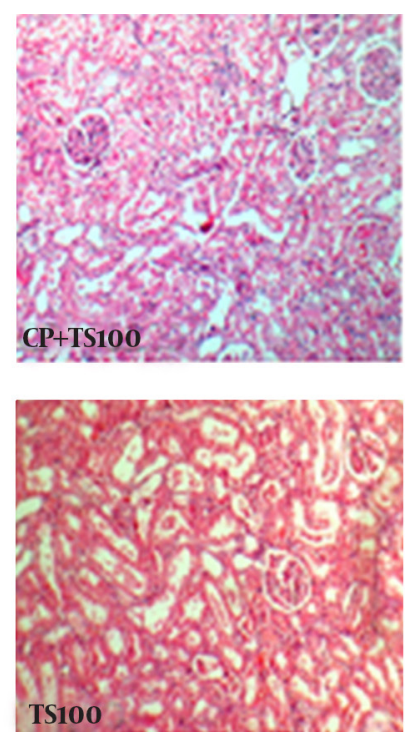
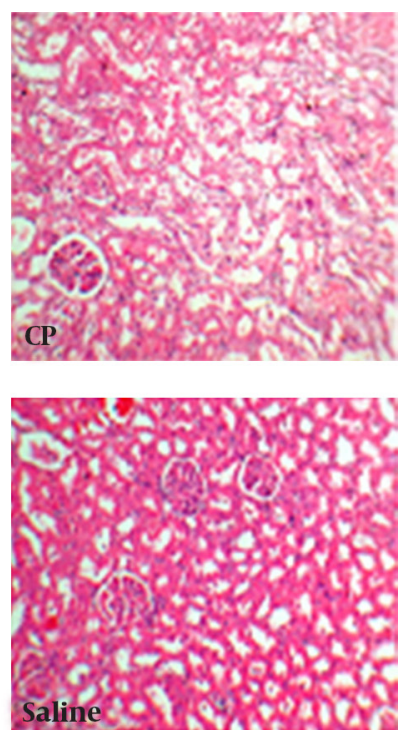

Hematoxylin and Eosin Staining, Magnification 100X

\section{Discussion}

The major finding of the present study was protective role of low-dose TS against CP-induced nephrotoxicity in castrated rats. Previous studies identified the role of estrogen in CP-induced nephrotoxicity (17), but the role of TS in CP-induced nephrotoxicity has not been welldocumented. The effect of CP on serum levels of BUN, Cr, and MDA, kidney damage, KW, and BW loss were reported (11, 21-28). In addition, decrease in the serum levels of nitrite and TS with CP has been demonstrated (29-31). The present study confirmed these findings. Despite orchiectomy and elimination of TS source, the serum level of remaining TS significantly decreased in group 4 in comparison with group 8 . This suggests that CP might cause a depression in serum TS level (31). In our study, the serum levels of BUN and $\mathrm{Cr}$ and kidney damage were decreased in low dose of TS plus CP treated group (group1) in comparison with the positive control group, which revealed the protective role of TS. It seems that TS at high doses did not have any protective role against $\mathrm{CP}$-induced nephrotoxicity and might acts as a toxic agent. In addition, we found that TS alone at high doses had raised serum level of MDA, KW, and KTDS while it had reduced BW significantly. Some researches demonstrated that in ischemia-reperfusion model, the serum level of $\mathrm{Cr}$ and proximal tubule injury might decrease in castrated rats that had received TS. Therefore, TS might protect the kidney from ischemia-reperfusion-induced acute kidney injury due to fast vasodilation effect on renal afferent arterioles, which is mediated by androgen receptors and activation of nitric oxide synthase due to an acute increase in glomerular filtration rate $(18,20)$. In addition, chronic diseases like obesity, hypertension, 
cardiovascular diseases, and chronic kidney disease (CKD) are associated with deficiency of TS in males (3236). Reduced TS levels in men with nondialysis CKD and in males on hemodialysis have been reported and TS deficiency aggravates cardiovascular events and increases arterial stiffness and mortality $(37,38)$. Furthermore, hypogonadism is a cause of anemia in men with CKD and TS replacement therapy decreases the prevalence of anemia in these patients (39). In the current study, the high dose of TS in TS alone treated rats (group 7) increased MDA level and KTDS. According to some studies, TS increases plasma MDA, as an oxidative stress parameter, and Cr. TS elevates kidney susceptibility to ischemiareperfusion injury through decreased activation of NOS and increased oxidative stress. It also promotes susceptibility of proximal tubule cells to apoptotic damage $(19,40,41)$. On the other hand, high dose of TS enhances oxidative stress and counteract antioxidant defense of myocardium (42). In the present study, high dose of TS decreased animal BW, which was similar to reported observation in human where TS replacement therapy in hypogonadal men led to loss of BW (43).

Our results suggest that TS in low doses plays a protective role against CP-induced nephrotoxicity and in high dose has a promoting role in nephrotoxicity; however, TS does not possess antioxidant properties at pharmacologic concentrations (44). It can be concluded that CP therapy should be avoided when serum TS level is high because TS in high concentrations promotes CP-induced nephrotoxicity.

\section{Acknowledgements}

We thank Isfahan University of Medical Sciences for supporting this research project (Grant \# 392522).

\section{Financial Disclosure}

The authors did not have any direct financial relation with the commercial identities mentioned in this article. Therefore, the authors had no conflict of interests

\section{References}

1. Arany I, Safirstein RL. Cisplatin nephrotoxicity. Semin Nephrol. 2003;23(5):460-4.

2. Miller RP, Tadagavadi RK, Ramesh G, Reeves WB. Mechanisms of Cisplatin nephrotoxicity. Toxins (Basel). 2010;2(11):2490-518.

3. Davis CA, Nick HS, Agarwal A. Manganese superoxide dismutase attenuates Cisplatin-induced renal injury: importance of superoxide. J Am Soc Nephrol. 2001;12(12):2683-90.

4. Luke DR, Vadiei K, Lopez-Berestein G. Role of vascular congestion in cisplatin-induced acute renal failure in the rat. Nephrol Dial Transplant. 1992;7(1):1-7.

5. Ramesh G, Reeves WB. TNF-alpha mediates chemokine and cytokine expression and renal injury in cisplatin nephrotoxicity. $J$ Clin Invest. 2002;110(6):835-42.

6. Winston JA, Safirstein R. Reduced renal blood flow in early cisplatin-induced acute renal failure in the rat. Am JPhysiol.1985;249(4 Pt 2):F490-6.

7. Appenroth D, Frob S, Kersten L, Splinter FK, Winnefeld K. Protective effects of vitamin $\mathrm{E}$ and $\mathrm{C}$ on cisplatin nephrotoxicity in developing rats. Arch Toxicol. 1997;71(11):677-83.
8. Bagnis C, Beaufils H, Jacquiaud C, Adabra Y, Jouanneau C, Le Nahour G, et al. Erythropoietin enhances recovery after cisplatininduced acute renal failure in the rat. Nephrol Dial Transplant. 2001;16(5):932-8.

9. Eshraghi-Jazi F, Nematbakhsh M, Nasri H, Talebi A, Haghighi M, Pezeshki Z, et al. The protective role of endogenous nitric oxide donor (L-arginine) in cisplatin-induced nephrotoxicity: Gender related differences in rat model. J Res Med Sci.2011;16(11):1389-96.

10. Mohamed HE, El-Swefy SE, Mohamed RH, Ghanim AM. Effect of erythropoietin therapy on the progression of cisplatin induced renal injury in rats. Exp Toxicol Pathol. 2013;65(1-2):197-203.

11. Saleh S, Ain-Shoka AA, El-Demerdash E, Khalef MM. Protective effects of the angiotensin II receptor blocker losartan on cisplatin-induced kidney injury. Chemotherapy. 2009;55(6):399-406.

12. Nematbakhsh M, Ashrafi F, Safari T, Talebi A, Nasri H, Mortazavi $\mathrm{M}$, et al. Administration of vitamin $\mathrm{E}$ and losartan as prophylaxes in cisplatin-induced nephrotoxicity model in rats. J Nephrol. 2012;25(3):410-7.

13. Soltani N, Nematbakhsh M, Eshraghi-Jazi F, Talebi A, Ashrafi F. Effect of oral administration of magnesium on Cisplatin-induced nephrotoxicity in normal and streptozocin-induced diabetic rats. Nephrourol Mon. 2013;5(4):884-90.

14. Saadat A, Shariat Maghani SS, Rostami Z, Davoudi A, Davoudi F, Shafie A, et al. Normobaric hyperoxia preconditioning ameliorates cisplatin nephrotoxicity. Ren Fail. 2014;36(1):5-8.

15. Nematbakhsh $M$, Talebi A, Nasri $H$, Safari T, et al .Some evidence for sex-based differences in cisplatin-induced nephrotoxicity in rats. Clin Exp Med Lett. 2012;53(1-2):29-32.

16. Nematbakhsh M, Ebrahimian S, Tooyserkani M, Eshraghi-Jazi F, Talebi A, Ashrafi F. Gender difference in Cisplatin-induced nephrotoxicity in a rat model: greater intensity of damage in male than female. Nephrourol Mon. 2013;5(3):818-21.

17. Pezeshki Z, Nematbakhsh M, Nasri H, Talebi A, Pilehvarian AA Safari T, et al. Evidence against protective role of sex hormone estrogen in Cisplatin-induced nephrotoxicity in ovarectomized rat model. Toxicol Int. 2013;20(1):43-7.

18. Lu Y, Fu Y, Ge Y, Juncos LA, Reckelhoff JF, Liu R. The vasodilatory effect of testosterone on renal afferent arterioles. Gend Med. 2012;9(2):103-11.

19. Kim J, Kil IS, Seok YM, Yang ES, Kim DK, Lim DG, et al. Orchiectomy attenuates post-ischemic oxidative stress and ischemia/reperfusion injury in mice. A role for manganese superoxide dismutase. JBiol Chem. 2006;281(29):20349-56.

20. Soljancic A, Ruiz AL, Chandrashekar K, Maranon R, Liu R, Reckelhoff JF, et al. Protective role of testosterone in ischemia-reperfusion-induced acute kidney injury. Am J Physiol Regul Integr Comp Physiol. 2013;304(11):R951-8.

21. Ammer U, Natochin Y, David C, Rumrich G, Ullrich KJ. Cisplatin nephrotoxicity: site of functional disturbance and correlation to loss of body weight. Ren Physiol Biochem. 1993;16(3):131-45.

22. Antunes LM, Darin JD, Bianchi MD. Protective effects of vitamin c against cisplatin-induced nephrotoxicity and lipid peroxidation in adult rats: a dose-dependent study. Pharmacol Res. 2000;41(4):405-11.

23. Deegan PM, Nolan C, Ryan MP, Basinger MA, Jones MM, Hande KR The role of the renin-angiotensin system in cisplatin nephrotoxicity. Ren Fail. 1995;17(6):665-74.

24. Saad SY, Najjar TA, Daba MH, Al-Rikabi AC. Inhibition of nitric oxide synthase aggravates cisplatin-induced nephrotoxicity: effect of 2-amino-4-methylpyridine. Chemotherapy. 2002;48(6):309-15.

25. Saleh S, El-Demerdash E. Protective effects of L-arginine against cisplatin-induced renal oxidative stress and toxicity: role of nitric oxide. Basic Clin Pharmacol Toxicol. 2005;97(2):91-7.

26. Stakisaitis D, Dudeniene G, Jankunas RJ, Grazeliene G, Didziapetriene J, Pundziene B. Cisplatin increases urinary sodium excretion in rats: gender-related differences. Medicina (Kaunas) 2010;46(1):45-50.

27. Pezeshki Z, Nematbakhsh M, Mazaheri S, Eshraghi-Jazi F, Talebi A, Nasri H, et al. Estrogen Abolishes Protective Effect of Erythropoietin against Cisplatin-Induced Nephrotoxicity in Ovariectomized Rats. ISRN Oncol. 2012;2012:890310. 
Rostami B et al.

28. Nematbakhsh M, Pezeshki Z, Eshraghi-Jazi F, Ashrafi F, Nasri H, Talebi A, et al. Vitamin E, Vitamin C, or losartan is not nephroprotectant against cisplatin-induced nephrotoxicity in presence of estrogen in ovariectomized rat model. International journal of nephrology. 2012;2012.

29. Ali BH, Al Moundhri MS. Agents ameliorating or augmenting the nephrotoxicity of cisplatin and other platinum compounds: a review of some recent research. Food Chem Toxicol. 2006;44(8):1173-83.

30. Maheshwari RA, Sailor GU, Patel L, Balaraman R. Amelioration of cisplatin-induced nephrotoxicity by statins. Indian J Pharmacol. 2013;45(4):354-8

31. Maines MD, Sluss PM, Iscan M. cis-platinum-mediated decrease in serum testosterone is associated with depression of luteinizing hormone receptors and cytochrome P-450scc in rat testis. Endocrinology. 1990;126(5):2398-406.

32. Allan CA, McLachlan RI. Androgens and obesity. Curr Opin Endocrinol Diabetes Obes. 2010;17(3):224-32.

33. Iglesias P, Carrero JJ, Diez JJ. Gonadal dysfunction in men with chronic kidney disease: clinical features, prognostic implications and therapeutic options. J Nephrol. 2012;25(1):31-42.

34. Malkin CJ, Pugh PJ, Morris PD, Asif S, Jones TH, Channer KS. Low serum testosterone and increased mortality in men with coronary heart disease. Heart. 2010;96(22):1821-5.

35. Rao SR, Kini S, Tamler R. Sex hormones and bariatric surgery in men. Gend Med. 2011;8(5):300-11.

36. Saad F. Androgen therapy in men with testosterone deficiency: can testosterone reduce the risk of cardiovascular disease? Diabetes Metab Res Rev. 2012;28 Suppl 2:52-9.
37. Kyriazis J, Tzanakis I, Stylianou K, Katsipi I, Moisiadis D, Papadaki A, et al. Low serum testosterone, arterial stiffness and mortality in male haemodialysis patients. Nephrol Dial Transplant. 2011;26(9):2971-7.

38. Yilmaz MI, Sonmez A, Qureshi AR, Saglam M, Stenvinkel P, Yaman $\mathrm{H}$, et al. Endogenous testosterone, endothelial dysfunction, and cardiovascular events in men with nondialysis chronic kidney disease. Clin J Am Soc Nephrol. 2011;6(7):1617-25.

39. Carrero JJ, Barany P, Yilmaz MI, Qureshi AR, Sonmez A, Heimburger $\mathrm{O}$, et al. Testosterone deficiency is a cause of anaemia and reduced responsiveness to erythropoiesis-stimulating agents in men with chronic kidney disease. Nephrol Dial Transplant. 2012;27(2):709-15

40. Park KM, Kim JI, Ahn Y, Bonventre AJ, Bonventre JV. Testosterone is responsible for enhanced susceptibility of males to ischemic renal injury. J Biol Chem. 2004;279(50):52282-92.

41. Verzola D, Gandolfo MT, Salvatore F, Villaggio B, Gianiorio F, Traverso $\mathrm{P}$, et al. Testosterone promotes apoptotic damage in human renal tubular cells. Kidney Int. 2004;65(4):1252-61.

42. Sadowska-Krepa E, Klapcinska B, Jagsz S, Sobczak A, Chrapusta SJ, Chalimoniuk M, et al. High-dose testosterone propionate treatment reverses the effects of endurance training on myocardial antioxidant defenses in adolescent male rats. Cardiovasc Toxicol. 2011;11(2):118-27.

43. Saad F, Haider A, Doros G, Traish A. Long-term treatment of hypogonadal men with testosterone produces substantial and sustained weight loss. Obesity (Silver Spring). 2013;21(10):1975-81.

44. Mooradian AD. Antioxidant properties of steroids. J Steroid Biochem Mol Biol.1993;45(6):509-11. 